\title{
CIRCULATING MICRORNA-615-5P AS A DIAGNOSTIC MOLECULAR MARKER IN EGYPTIAN PATIENTS WITH LIVER CIRRHOSIS
}

\author{
Mofida A. Keshk ${ }^{1}$, Hisham A. Ismail ${ }^{1}$, Mahmoud I. Nasr ${ }^{2}$, Moustafa A Sakr¹, Fawzy M. Khalil ${ }^{3}$, Mohamed \\ El-Assal ${ }^{3}$, Ahmed M.Hussein ${ }^{3}$, Shuzan A. Mohammed ${ }^{4}$, Mohamed Y. Nasr ${ }^{1}$. \\ ${ }^{1}$ Molecular diagnostics and therapeutics department, Genetic Engineering and Biotechnology Research Institute \\ (GEBRI), University of Sadat City, Egypt. \\ ${ }^{2}$ Molecular biology department, Genetic Engineering and Biotechnology Research Institute (GEBRI), University \\ of Sadat City, Egypt \\ ${ }^{3}$ Internal Medicine Department, Faculty of Medicine, Benha University, Egypt \\ ${ }^{4}$ Medical Biochemistry Department, Faculty of Medicine, Benha University, Egypt \\ Corresponding author: Mofida keshk (mofida.keshk@gebri.usc.edu.eg)
}

\begin{abstract}
Background: Liver cirrhosis has emerged as a major cause of global health burden. The vast majority (80-90\%) of HCCs develop in a cirrhotic liver. Liver cirrhosis and HCC due to chronic hepatitis C are among the main indications for liver transplantation. The confront in the $21^{\text {st }}$ century is to prevent the need for liver transplantation in cirrhotic patients as much as possible. Due to the unique situation of hepatitis $\mathrm{C}$ virus (HCV) in Egypt, being plagued with the highest HCV prevalence in the world, a considerable increase was observed in the proportion of chronic liver disease in Egyptian patients. Liver biopsy has traditionally been the "gold standard" test; it is an invasive procedure with rare but potentially life-threatening complications. These limitations rapidly reduced its use to the sake of developing non-invasive methods as indices and imaging. Alpha fetoprotein (AFP) is seen as the commonest and feasible marker for assessing liver cirrhosis; however, it is not completely reliable because of its low specificity and sensitivity. In early cirrhosis, however, conventional imaging can lead to false-negative diagnosis so other strategies are urgently needed. Currently, lack of robust biomarkers still limits evaluation of hepatic failure and progression in chronic diseases, especially in HCV infection. Aim: the main objective of the present study was to evaluate the significance of a new, non-invasive molecular marker, microRNA-615-5p (miR615-5p) in circulating blood for diagnosing liver cirrhosis arising from HCV infection. Methods: A total of 50 blood samples were collected; 30 samples from hepatic cirrhotic patients, 10 samples from chronic HCV hepatitis patients and 10 control samples. The level of circulating miRNA-615-5p was detected by RT-qPCR in all samples. Besides, miR-615-5p levels in relation to clinical laboratory parameters were explored. Results: The expression of circulating miR-615-5p was distinctly increased in hepatic cirrhosis with HCV chronic patients compared with control group (mean $\pm \mathrm{SE}$ : 5.44 $\pm \mathbf{0 . 0 2}, P<\mathbf{0 . 0 1}$ and $4.9 \pm 0.01, P<0.01$, respectively). Receiver Operator Characteristic (ROC) curve analysis revealed much higher specificity and sensitivity for the circulating miR-615$5 p$ in comparison to the traditional AFP. Conclusions: The results showed that miR-615-5p might be a potential molecular biomarker for diagnosing liver cirrhosis, implying that it could be even used as a novel non-invasive molecular biomarker for predicting HCV-related liver cirrhosis.
\end{abstract}

Key words: Liver cirrhosis, miR-615-5p, non-invasive marker, Egyptians.

\section{INTRODUCTION}

Following long-term liver injury, the evolution of liver fibrosis to cirrhosis is associated with (i) architectural disturbance; (ii) angiogenesis and hemodynamic changes (intra- and extra-hepatic) resulting in portal hypertension; (iii) a propensity for carcinogenesis [1]. Liver fibrosis is part of the structural and functional alterations in most chronic liver diseases. It is one of the major prognostic factors as the amount of fibrosis is correlated with the risk of emergent cirrhosis and liver-related complications in viral and non-viral chronic liver diseases [2]. Cirrhosis can occur in consequence of 
an exogenous/toxic, infectious, toxic/allergic, immunopathological/autoimmune, or vascular process or an inborn error of metabolism [3].

Cirrhosis is the final stage gained by various chronic liver diseases after years or decades of slow progression. There are, however, ways to avoid cirrhosis, because the diseases that most commonly lead to it progress slowly, and measures are accessible to prevent and treat them. Moreover, most cases of hepatocellular carcinoma (HCC) arise in a cirrhotic liver, so cirrhosis prevention is, in fact, also HCC prevention [4].

The epidemiology of liver cirrhosis has been evaluated widely in several developed countries in Europe and the Americas. There has been much less interest in mortality from the disease, though, in much of the developing world [5-8], in part because of poor data [9]. Liver cirrhosis deaths worldwide have increased progressively over the past 30 years [9]. In 2010, liver cirrhosis ranked as the $23^{\text {rd }}$ cause of disease saddle worldwide [10]. On average, there were twice as many liver cirrhosis male deaths as female deaths. Age-standardized liver cirrhosis mortality rates and time trends in Europe followed a strong 'East-to-West gradient', as identified by Zatonski et al. [7].

Cirrhosis and HCC due to chronic hepatitis C are amongst the main indications for liver transplantation in Western manufacturing countries. From 1988 to 2010, viral hepatitis was the underlying cause of liver disease in $39 \%$ of liver transplant recipients-hepatitis $B$ in one-third of cases, and hepatitis $C$ in two-thirds [11].

In Egypt, cure for schistosomiasis until the late 1960s led to widespread transmission of the hepatitis C virus [12]. Currently, Egypt has the highest prevalence of chronic hepatitis $C$ infection in the world $[13,14]$. This is reflected in the very high liver cirrhosis death rates, particularly in males. In 2010, the age-standardized cirrhosis mortality rate in Egypt was the highest internationally at 72.7 (57.2 to 87.2 ) per 100,000 . During the same year, $18 \%$ of deaths in males between ages 45 to 54 years were due to liver cirrhosis [9].

Cirrhosis has long been known by the development of acute deterioration of liver and/or renal function, hepatic encephalopathy and high risk of hospital mortality in connection to a precipitating event, commonly an infection [15]. For several years, liver biopsy has been considered the "gold standard" test [16]. Liver biopsy analysis has several limitations. It is an invasive procedure with rare but potentially life-threatening complications and prone to sampling errors and to intra- and inter-observer variation [17]. These limitations have rapidly decreased the use of liver biopsy and led to the development of non-invasive methodologies. Among the currently accessible non-invasive methods, there are two distinct approaches: (i) a "biologic" approach based on the quantity of serum biomarkers of fibrosis; (ii) a "physical" approach based on the measurement of liver stiffness using transient elastography (TE) [18]. Although complementary, these two approaches are based on differing rationale and conception: TE measures liver stiffness related to elasticity, which corresponds to physical property of liver parenchyma, whereas serum biomarkers are combinations of several not strictly liver-specific blood parameters optimized to mimic fibrosis stages as assessed by liver biopsy [19]. Overall, biomarkers are less accurate in detecting intermediate stages of fibrosis than cirrhosis [20].

Among the proposed markers, the so-called direct markers reveal the deposition or removal of extracellular matrix in the liver. These include glycoproteins such as serum hyaluronate, laminin, and YKL-40, collagens such as procollagen III Npeptide and type IV collagen, collagenases, and their inhibitors such as matrix metalloproteases and tissue inhibitory metalloprotease-1. So-called indirect markers include factors that can be calculated in routine blood tests, such as the prothrombin index, platelet count, and ratio of aspartate transaminase to alanine transaminase (AST : ALT), which indicate alterations in hepatic function. Outcome from measurements of direct and indirect markers can be combined and used in diagnosis; the FibroTest ${ }^{\circledR}$ (BioPredictive, Paris, France) was the first algorithm that combined these data [21]. Several other scores have been proposed - four are sheltered by patents- and commercially available [22-31].

When compared and validated externally in patients with hepatitis $C$ virus infection, the different patented scores have similar performances for the diagnosis of cirrhosis [32- 36]. In the largest study to date ( $n=1307$ patients with viral hepatitis) comparing prospectively the most popular patented scores (FibroTest ${ }^{\circledR}$, FibroMeter $^{\circledR}$, HepaScore ${ }^{\circledR}$ ) with the non-patented score (APRI), the mean area under the receiver operating characteristic curve (AUROC) ranged from from 0.77 to 0.86 with no significant difference between the scores [36]. Although nonpatented scores such as FIB-4 and APRI may have slightly lower performance, they are cost-free, easy to calculate, and available almost everywhere [37- 
40]. However, none are liver specific, their results can be influenced by comorbid conditions and they require critical explanation of the results [41].

In early cirrhosis, however, usual imaging can lead to false-negative diagnosis (42), and TE applicability is not as good as that of serum biomarkers (43). Combining TE with biomarkers does not increase diagnostic accuracy for cirrhosis in patients with persistent hepatitis C virus infection [44- 46], so other strategies are needed.

Emerging evidence indicates that the newly discovered non-coding short RNAs (microRNAs) deregulation have contributed greatly to the epigenetic-based liver diseases [47] that function by regulating the activity of mRNA targets and thus play important roles in a wide range of physiological and pathologic processes. Some miRNAs are formed in cell- or tissue-specific manners. Consequently, miRNA changes within a tissue type might correlate with certain disease states. Moreover, miRNAs are present in the peripheral blood in a remarkably stable form; thus, they might serve as potential blood-based biomarkers [48].

In this study, we investigated: the expression of circulating miR-615-5p in patients with cirrhosis on top of HCV-chronic infection, the potential role of miR-615-5p as a diagnostic non-invasive molecular marker for liver cirrhosis and assessed its sensitivity and specificity in comparing with the conventional marker AFP in a trial to weave the need for biopsy.

\section{SUBJECTS AND METHODS}

This study was conducted on 50 Egyptian subjects who were divided into 30 patients (20 are males) with liver cirrhosis on top of HCV with a mean age ( \pm SE) of $(58.37 \pm 0.9$ ) years, 10 patients ( 5 males) of chronic HCV without fibrosis, with a mean age of $(55.3 \pm 1.4)$ years, and blood samples were also collected from 10 age- and gender-matched healthy volunteers (defined as those with normal liver function test (LFT) and negative for $\mathrm{HBs} \mathrm{Ag}, \mathrm{HBc}-\mathrm{Ab}$ and HCV Ab with a mean age of $(55.1 \pm 1.6)$ years. All subjects were recruited from the Hepatology \& Gastroenterology and Infectious Diseases Department, Benha University Hospital, Benha University.

Liver cirrhosis with HCV diagnosis was based on standard clinical, biochemical, serological, and ultrasonography. Diagnosis of HCV-associated chronic liver disease (CLD) was based also on standard clinical, biochemical and serological criteria. These group members were proved to be not fibrotic by applying FIB-4 index (28).
All patients and controls were subjected to full history taking. Exclusion criteria included: cases of chronic HBV infection, autoimmune hepatitis, metabolic liver diseases (haemochromatosis, Wilson's disease, nonalcoholic steatohepatitis), history of alcohol consumption, previous treatment for HCC or antiviral therapy and any associated malignancies other than HCC. The study was approved by Benha University Hospital research ethics committee and has been performed in accordance with the ethical standards of the Declaration of Helsinki. An informed consent was obtained from all individual participants included in the study.

\section{Clinical Laboratory tests}

For all participants, the following was conducted: clinical evaluation (medical history and physical examination), complete blood count, liver function tests, and prothrombin time, AFP, abdominal US examination- except for control group-, testing for hepatitis $B$ surface antigen ( $\mathrm{HBs} \mathrm{Ag}$ ) and hepatitis $\mathrm{C}$ antibody (HCV-Ab).

\section{Molecular test for miR-615-5p}

Total RNA, including low molecular weight RNAs, were extracted from all participants using RNeasy Protect Animal Blood kit (QIAGEN, Germany) according to the manufacturer's instructions. The quality of RNA was determined using NanoDrop2000 (Thermo scientific, USA). Then single-stranded cDNAs were generated on $10 \mathrm{ng}$ of total RNA in a final volume $15 \mu \mathrm{RT}$ reactions $\left(16^{\circ} \mathrm{C}\right.$ for $30 \mathrm{~min}, 42{ }^{\circ} \mathrm{C}$ for $30 \mathrm{~min}$ and $85^{\circ} \mathrm{C}$ for $5 \mathrm{~min}$ ) using TaqMan reverse transcription kit; TaqMan ${ }^{\circledR}$ Small RNA Assays (Applied Biosystems, California, USA) according to the manufacturer's instructions. Then cDNA was preserved at $4^{\circ} \mathrm{C}$ till needed.

Expression levels of microRNA-615-5p was evaluated using TaqMan $^{\circledR}$ Small RNA Assays (Applied Biosystems, California, USA) as follows: 1.3 $\mu \mathrm{L}$ from its corresponding $\mathrm{RT}$ reaction (CDNA) were mixed in a mixture of $10 \mu \mathrm{L}$ TaqMan Universal PCR Master Mix II with $1.00 \mu \mathrm{L}$ ready-made primer (20X) and $7.7 \mu \mathrm{L}$ nuclease-free water in a total volume of $20 \mu \mathrm{L}$ per reaction. The expression levels were normalized to RNU6B levels. All reactions were run on 7900HT Fast Real-Time PCR System (Applied Biosystems, USA) using the following conditions: $95^{\circ} \mathrm{C}$ for 10 minutes once, then 40 cycles of: denaturation $\left(95^{\circ} \mathrm{C}\right.$ for $15 \mathrm{sec}$.), annealing $\left(60^{\circ} \mathrm{C}\right.$ for $60 \mathrm{sec}$.) and extension $\left(60^{\circ} \mathrm{C}\right.$ for $60 \mathrm{sec}$.). Relative expression of miRNA-615-5p was calculated using the comparative cycle threshold $(\mathrm{Ct})$ method. $\Delta \mathrm{CT}$ 
was calculated by subtracting the $\mathrm{Ct}$ values of RNU6B from the $\mathrm{Ct}$ values of the selected miRNA615-5p samples. $\Delta \Delta^{\mathrm{Ct}}$ was then calculated by subtracting mean $\triangle C T$ of the control samples from $\triangle C T$ of tested samples. Fold change of miRNA expression levels was calculated using the formula $2^{-\Delta \Delta C t}$ using healthy controls as calibrators.

\section{Statistical analysis:}

All statistical analyses were performed using Statistical Package for Social Science (SPSS) version 17 (SPSS Inc., Chicago, IL, USA). Data are presented as means with corresponding standard error (SE). Comparisons between different groups were performed by one-way analysis of variance (ANOVA). Tukey's test was used as a posthoc test. Correlation among variables was determined using Pearson's correlation test. The performance of a noninvasive diagnostic method is evaluated by calculation of the area under the receiver operator characteristic curve (AUROC) taking AFP as the reference standard (MedCalc v. 16.4). In all tests, the level of significance was set at $P<0.05$.

\section{RESULTS AND DISCUSSION}

\section{Population and clinical studies:}

Demographic, biochemical, and hematological characteristics of the patients are summarized in table (1). The mean ages ( $\pm \mathrm{SE}$ ) of control, chronic non-cirrhotic hepatitis $C$ patients and cirrhotic liver patients were $(55.1 \pm 1.6,55.3 \pm 1.4,58.37 \pm 0.9)$ years, respectively and proved to be nonsignificant ( $P>0.05$ ). Gender was nonsignificant between studied groups $(P>0.05)$. A positive correlations were observed between ALT, AST, GGT, ALP, total bilirubin, direct bilirubin, INR, AFP, miR-615-5p and the progress of the disease to cirrhosis. Inversely, there were negative correlations between: albumin, platelet count, hemoglobin level and progression of the disease to cirrhosis, while WBCs was nonsignificantly correlated to cirrhotic group.

Table (1): Demographic, biochemical, and hematological parameters of the three studied groups.

\begin{tabular}{|c|c|c|c|}
\hline & \multicolumn{3}{|c|}{ Mean \pm SE } \\
\hline & Control $(n=10)$ & Non-Cirrhotic $(n=10)$ & Cirrhotic $(n=30)$ \\
\hline
\end{tabular}

Age: Range (Mean)

48-63(55.1)

Demographic Data

Gender

Male

Female

$5(50 \%)$

$5(50 \%)$

Biochemical parameters

$\begin{array}{ll}\text { ALT (up to 40 U/L) } & (21.9 \pm 1.2) \\ \text { AST (up to 40U/L) } & (23.7 \pm 1.4) \\ \text { GGT (up to 50 U/L) } & (15.1 \pm 1.03) \\ \text { ALP (up to } 115 \mathrm{U} / \mathrm{L}) & (52 \pm 5.1) \\ \text { Total Bil. (up to } 1 \mathrm{mg} / \mathrm{dL}) & (0.89 \pm 0.03) \\ \text { Direct Bil. (up to } .25 \mathrm{mg} / \mathrm{dL}) & (0.18 \pm 0.01) \\ \text { Albumin }(3.5: 5.5 \mathrm{gm} / \mathrm{dL}) & (4.42 \pm 0.17)\end{array}$

\section{Hematological parameters}

Plat. (150:450x 103/ $\mathrm{mm}^{3}$ )

INR

WBCs (3.9: $\left.11 \times 10^{3} / \mathrm{mm}^{3}\right)$

$\mathrm{Hgb}(11.5: 16.5 \mathrm{gm} / \mathrm{dL})$

$$
\text { 49-64(55.3) }
$$

49-68(58.37)

N.S.

$5(50 \%)$

$5(50 \%)$

$20(66.7 \%)$

$10((33.3 \%)$

N.S.
$(45.2 \pm 6.8)^{1^{*}}$
$(36.8 \pm 4.4)$
$(52.2 \pm 11.7)$
$(98.5 \pm 5.7)^{1 \text { ** }}$
$(0.53 \pm 0.08)$
$(0.17 \pm 0.02)$
$(4.64 \pm 0.09)$
$(53.5 \pm 3.8)^{1^{* * *}}$
$(72.5 \pm 4.9)^{1 * *, 2 * *}$
$(147.3 \pm 12)^{1 * *, 2^{* * *}}$
$(104.63 \pm 3.4)^{1 * *}$
$(4.13 \pm 0.5)^{1 * *, 2 * *}$
$(1.91 \pm 0.29)^{1 * *, 2^{* * *}}$
$(2.54 \pm 0.06)^{1 * *, 2 * *}$

$<0.01$

$<0.01$

$<0.01$

$<0.01$

$<0.01$

$<0.01$

$<0.01$

$\begin{array}{ll}(104.9 \pm 7.6)^{1 * *, 2^{* * *}} & <0.01 \\ (1.49 \pm 0.07)^{1 * *, 2^{* * *}} & <0.01 \\ (8.2 \pm 0.6) & \text { N.S. } \\ (9.87 \pm 0.3)^{1 * *, 2^{* * *}} & <0.01\end{array}$

\footnotetext{
cirrhotic group. NS: nonsignificant. $*=$ statistical significant differenc

e $<0.05$ and $* *=$ statistical significant difference $<0.01$

Special volume for the first International Conference of Genetic Engineering and Biotechnology,

Sharm el Shiekh, Egypt. 26-29 April, 2016.
}

${ }^{1}$ denotes statistically significant difference from control. ${ }^{2}$ denotes statistically significant difference from non- 


\section{Circulating miR-615-5 and AFP levels in cases and controls}

Blood level of miR-615-5p expression was detected in cirrhotic cases and other groups normalized to RNU6B as an internal control. As shown in (Fig. 1, table 2), we found that the expression of miR-615$5 p$ was not significantly increased in "non-cirrhotic" chronic HCV group comparing to the control group (mean \pm SE: $4.94 \pm 0.03,4.9 \pm 0.01$ respectively); whereas the blood level of miR-615-5p expression was significantly increased in cirrhotic group in comparison to the control group (mean \pm SE: $5.44 \pm 0.02$ vs. $4.9 \pm 0.01$ ) and also to the non-cirrhotic groups (mean \pm SE: $5.44 \pm 0.02$ and $4.94 \pm 0.03$ ), respectively. This progressive increase in miR-615$5 p$ expression observed in the cirrhotic patients was more than 5-fold enhancement than the control. There was also a significant difference in AFP levels also increased in progression to liver cirrhosis in a positive way (Fig. 2, table 2).

3.3. Correlation between circulating miRNA-615$5 p$, AFP and other parameters:
Pearson's correlation between both: miR-615-5p, AFP levels and the liver function test (LFT) parameters in the cirrhotic group (table: 3 ). There were significant correlations between AST ( $r=0.57$ $\& P<0.01)$, total bilirubin $(r=0.5 \& P<0.01)$, direct bilirubin $(r=0.37 \& P<0.05)$ and miR-615-5P geneexpression, while in the same group, there was only a significant positive correlation between AFP and AST $(r=0.434 \& P<0.05)$.

\subsection{Accuracy of circulating miRNA-615-5p in Cirrhotic patients}

Accuracy of using miR-615-5p and AFP as a diagnosing tool for liver cirrhosis was deducted by applying the ROC curve analysis (MedCalc v.16.4), shown in fig (3). It was obviously denoted that our tested microRNA was more accurate than AFP; possessed more area under curve (AUC). This was translated into higher specificity and more sensitivity (98.5\% and $93.33 \%$ respectively) than the traditionally requested AFP $(90 \%$ and $86.7 \%$, respectively). PPV and NPV also showed much more values to the sake of the newly tested miR-615-5p (table: 4).

Table (2) Comparison of miR-615-5P and AFP expression levels in all studied groups

\begin{tabular}{|c|c|c|c|c|}
\hline \multirow{2}{*}{ Variables } & \multicolumn{3}{|c|}{ Mean $\pm \mathrm{SE}$} & \multirow[b]{2}{*}{$P$ value } \\
\hline & Control & Non-cirrhotic & $\overline{\text { Cirrhotic }}$ & \\
\hline Log RU for miR-615-5P Fold & $(4.9 \pm 0.01)$ & $(4.94 \pm 0.03)$ & $(5.44 \pm 0.02)^{1 * *, 2 * *}$ & $<0.01$ \\
\hline $\mathrm{AFP}$ (up to $10 \mathrm{ng} / \mathrm{ml}$ ) & $(6 \pm 0.88)$ & $(32.07 \pm 3.7)$ & $(105.21 \pm 12.3)^{1 * *, 2 * *}$ & $<0.01$ \\
\hline
\end{tabular}

${ }^{1}$ denotes statistically significant difference from control. ${ }^{2}$ denotes statistically significant difference from noncirrhotic group. $* *=$ statistical significant difference $<0.01$ 
Table (3): Pearson's correlation between laboratory investigated parameters in the cirrhotic group.

\begin{tabular}{llc}
\hline \multirow{2}{*}{ Variables } & \multirow{2}{*}{ AFP } & miR-615-5P (Log RU) \\
\cline { 2 - 3 } & \multicolumn{2}{c}{$\boldsymbol{r}$} \\
\hline ALT $(\sim 40 \mathrm{U} / \mathrm{L}$ & 0.325 & 0.341 \\
AST $(\sim 40 \mathrm{U} / \mathrm{L})$ & $0.434^{*}$ & $0.57 *$ \\
GGT $(\sim 50 \mathrm{U} / \mathrm{L}$ & 0.200 & 0.215 \\
ALP $(\sim 115 \mathrm{U} / \mathrm{L})$ & 0.066 & 0.25 \\
Total Bil. $(\sim 1 \mathrm{mg} / \mathrm{dL}$ & 0.102 & $0.503 * *$ \\
Direct Bil. $(\sim .25 \mathrm{mg} / \mathrm{dL})$ & 0.031 & $0.371 *$ \\
Albumin $(3.5: 5.5 \mathrm{gm} / \mathrm{dL})$ & -0.232 & -0.096 \\
Plat. $\left(150: 450 \times 10^{3} / \mathrm{mm}{ }^{3}\right)$ & -0.351 & -0.262 \\
INR & 0.183 & 0.141 \\
WBCs $\left(3.9: 11 \times 10^{3} / \mathrm{mm}^{3}\right)$ & 0.115 & 0.049 \\
Hgb $(11.5: 16.5 \mathrm{gm} / \mathrm{dL})$ & -0.128 & -0.165 \\
& & \\
r $=$ Correlation coefficient, negative values intended negative correlation \\
$*$ show statistical significant difference $(P<0.05)$ while $* *$ show statistical \\
significant difference $(P<0.01)$ in the cirrhotic group.
\end{tabular}

\section{LOGRU MIR-615-5P}

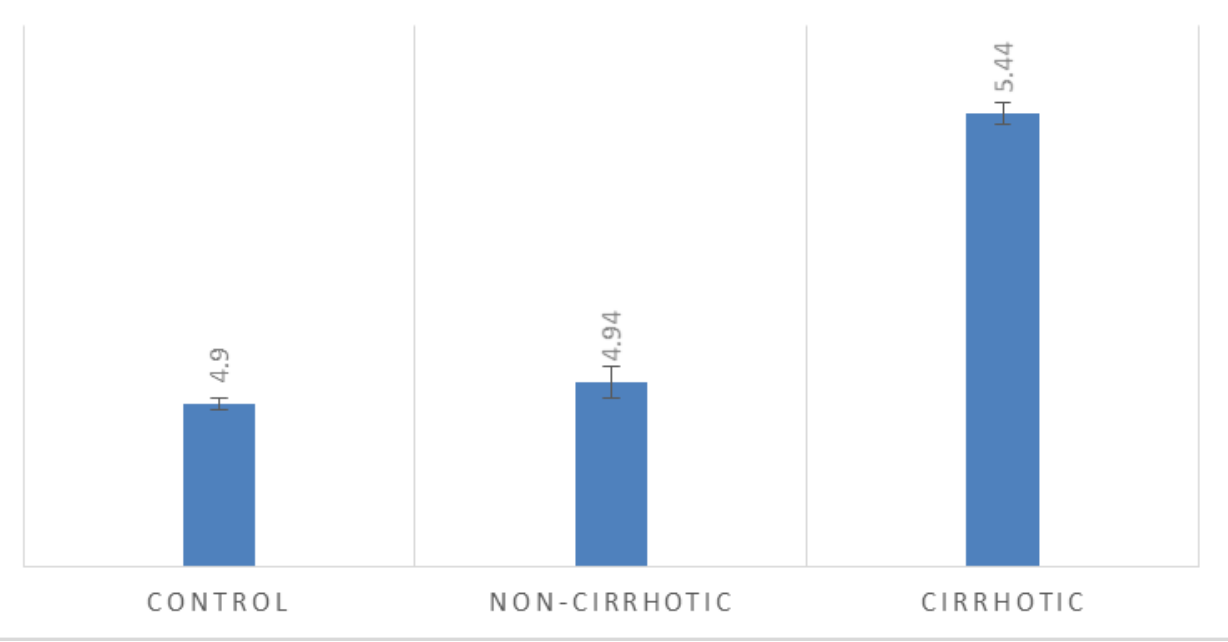

Fig. (1): Expression level of "miR-615-5p" in the three studied groups. 


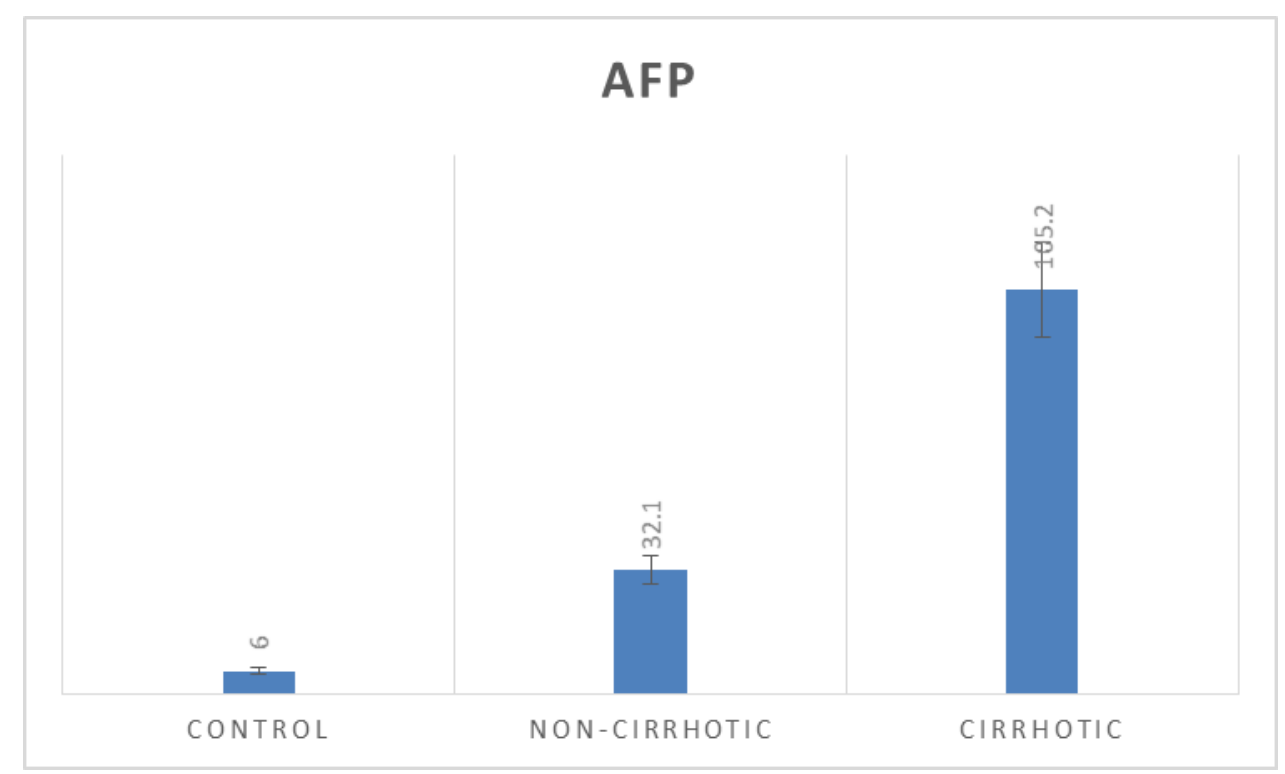

Fig. (2): Expression level of "AFP" in the three studied groups.

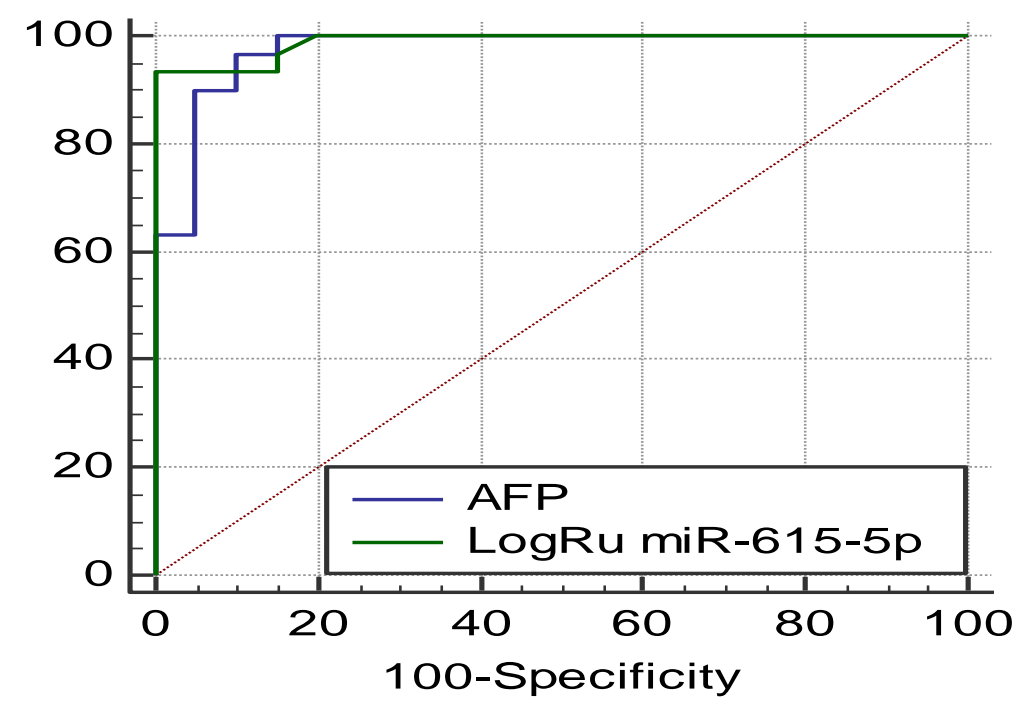

Fig. (3): ROC curve for performance of the studied miRNA-615-5p and AFP in early detection of liver cirrhosis.

Table 4: Predictive performance of both AFP and miR-615-5p for liver cirrhosis.

\begin{tabular}{|l|c|c|c|r|r|r|r|r|c|}
\hline VariableT & Cutoff & Sens.\% & Spec.\% & PPV\% & NPV\% & Accuracy & AUC & 95\% CI & $\boldsymbol{P}$ \\
\hline AFP $(\mathrm{ng} / \mathrm{mL})$ & $>49$ & $86.7 \%$ & $90 \%$ & $93.3 \%$ & $78 \%$ & $88 \%$ & 0.89 & $0.87-0.94$ & $<0.01$ \\
\hline $\begin{array}{l}\text { miR-615-5p } \\
\text { (Fold-expressed) }\end{array}$ & $>5.2$ & $93.3 \%$ & $98.5 \%$ & $97 \%$ & $83.3 \%$ & $95 \%$ & 0.99 & $0.9-1.00$ & $<0.01$ \\
\hline
\end{tabular}

Liver cirrhosis has emerged as a major cause of worldwide health burden $[\mathbf{1 0}, \mathbf{4 9}]$. It represents the strongest predisposing factor, as about $80 \%$ of HCCs develop in cirrhotic livers [50].
Serum AFP was dropped out from guidelines due to its poor sensitivity (39-65\%) [51], and since repeating MRI and $\mathrm{CT}$ scans may represent a problem in terms of 
economic and personnel resources, the availability of reliable biomarkers, to be assayed over time, would represent an aid to the assessment of the malignant potential of liver nodules on cirrhosis. For these reasons, this field of research has been highlighted by both EASL-EORTC and AASLD guidelines as a priority. In cases not characterized by imaging techniques, biopsy is recommended even though it involves the risks of invasive procedures; no circulating biomarker contributing to the early detection is recommended at the moment $[52,53]$.

Circulating microRNAs have been demonstrated to be highly stable in serum and plasma due to their protection from RNase activity, therefore representing a possible source of diagnostic and prognostic biomarkers to be explored [54], especially for detection of early stage, presymptomatic diseases [55]. Gui et al [56] identified a panel of miRNAs up-regulated in patients with liver cirrhosis. For example, it was mentioned that miR-155 was markedly elevated in cirrhotic tissues; miR-155 showed increased expression in cirrhotic tissues compared to healthy tissues [57] and miR-595 and miR-765 were shown to be among the most recent identified miRNAs in cirrhotic patients [54].

miR-615-5p is a very novel microRNA that was once analyzed in prostate cancer cell lines where it showed high expression [58]. El-Tyebi et al, (57) were the first who investigated miR-615-5p in liver cirrhotic patients in Egypt in an approach to screen for the presence of it in healthy, cirrhotic and cancerous liver tissues as well as HCC cell lines, and they proved its expression in the cirrhotic tissues. The expressed level of miR-615-5p in circulating blood has never been studied before in liver cirrhotic patients, that makes it a potential target for further analysis. The present study is in agreement with El-Tyebi et al, (57) in that circulating miR-615-5p is highly expressed in cirrhotic patients compared to healthy persons. In terms of the expression status of miR-615-5p in cirrhotic patients compared with normal control, our study was in contrast with El Tayebi et al. [57] where miR-615-5p was detected as significantly expressed in normal tissues in comparison with cirrhotic cases.

ROC curve was conducted and the AUC was calculated to explore the predicting and/or diagnostic value of the studied miRNA (miR-615-5p) for differentiating cirrhotic patients from the non-cirrhotic ones. AUC for miR-615-5p was higher (0.99) than that of AFP (0.89). The concluded result was near perfect in diagnosing cirrhosis in comparison to the conventional requested AFP. The specificity and sensitivity of both miR-615-5p and AFP were $(98.5 \%$ vs. $90 \%$ and $93.3 \%$ vs. $86.7 \%$, respectively) which enable us to apply the cut-off value of miR-615-5p (>5.2 expression fold) as a predicting marker for liver cirrhosis among Egyptians especially those of high risk population.

In conclusion, our data suggests -for the first time- that miR-615-5p might potentially serve as novel, sensitive molecular biomarker for diagnosing or even predicting cirrhosis of the liver before progressing to the most serious disease HCC, which would have a better outcome on the health of those suffering from this silent disease.

\section{REFERENCES}

1. Vergniol J, Foucher J, Terrebonne E et al. (2011): “Noninvasive tests for fibrosis and liver stiffness predict 5-year outcomes of patients with chronic hepatitis C," Gastroenterology; 140 (7): 1970.e31979.e3.

2. Younossi ZM, Stepanova $M$, Rafiq $N$, Makhlouf H, Younoszai Z, Agrawal R, et al. (2011): Pathologic criteria for nonalcoholic steatohepatitis: interprotocol agreement and ability to predict liver-related mortality. Hepatology; 53: 1874- 82.

3. Wiegand J and Berg T (2013): The Etiology, Diagnosis and Prevention of Liver Cirrhosis. Dtsch Arztebl Int; 110(6): 85-91.

4. Manns MP, Czaja AJ, Gorham JD, et al. (2010): Diagnosis and management of autoimmune hepatitis. Hepatology; 51: 2193- 213.

5. Bosetti C, Levi F, Lucchini F, Zatonski WA, Negri E and La Vecchia C (2007): Worldwide mortality from cirrhosis: an update to 2002. J Hepatol; 46:827-39.

6. Corrao G, Ferrari $P$, Zambon A, Torchio P, Aricò S and Decarli A (1997): Trends of liver cirrhosis mortality in Europe, 19701989: age-period-cohort analysis and changing alcohol consumption. Int J Epidemiol; 26:100-9. 
7. Zatoński WA, Sulkowska U, Mańczuk M, Rehm J, Boffetta P, Lowenfels AB and La Vecchia C (2010): Liver cirrhosis mortality in Europe, with special attention to Central and Eastern Europe. Eur Addict Res; 16:193- 201.

8. La Vecchia C, Levi F, Lucchini F, Franceschi $S$ and Negri E (1994): Worldwide patterns and trends in mortality from liver cirrhosis, 1955 to 1990. Ann Epidemiol; 4:480- 6 .

9. Mokdad A A, Lopez A D, Shahraz S, Lozano R, Mokdad A H, Stanaway J, Murray C J and Naghavi M (2014): Liver cirrhosis mortality in 187 countries between 1980 and 2010: a systematic analysis. BMC Medicine; 12: 145.

10. Murray CJ, Vos $T$, Lozano R, Naghavi M, Flaxman $A D$, Michaud $C$, Ezzati $M$, Shibuya K, Salomon JA, Abdalla $S$, Aboyans V, Abraham J, Ackerman I, Aggarwal R, Ahn SY, Ali MK, Alvarado M, Anderson HR, Anderson LM, Andrews KG, Atkinson C, Baddour LM, Bahalim AN, Barker-Collo S, Barrero LH, Bartels DH, Basáñez MG, Baxter A, Bell ML, Benjamin EJ, et al (2012): Disability-adjusted life years (DALYs) for 291 diseases and injuries in 21 regions, 1990-2010: a systematic analysis for the Global Burden of Disease Study 2010. Lancet; 380:2197223.

11. European Liver Transplant Registry; 2012.

12. Frank $C$, Mohamed $M K$, Strickland G $T$, Lavanchy D, Arthur R R, Magder L S, El Khoby T, Abdel-Wahab Y, Aly Ohn E S, Anwar W, Sallam I (2000): The role of parenteral antischistosomal therapy in the spread of hepatitis C virus in Egypt. Lancet; 355:887-91.

13. Shepard C W, Finelli L, Alter M J (2005): Global epidemiology of hepatitis $C$ virus infection. Lancet Infect Dis; 5:558-67.

14. Ray K W: Global epidemiology and burden of hepatitis C (2002): Microbes Infect; 4:1219- 25.
15. Arroyo $V$, Moreau $R$, Jalan $R$ and Ginès $P$ (2015): Acute-on-chronic liver failure: $A$ new syndrome that will re-classify cirrhosis. Journal of Hepatology; 62: S131-S143.

16. Bravo A, Sheth G, Chopra S (2001): Liver biopsy. N Engl J Med; 344: 495- 500.

17. Halfon $\mathbf{P}$, Bacq $Y$, De Muret $A$, et al. (2007): Comparison of test performance profile for blood tests of liver fibrosis in chronic hepatitis C. J Hepatol; 46: 395402.

18. Castera L and Pinzani M (2010): Noninvasive assessment of liver fibrosis: are we ready? Lancet; 375: 1419- 20.

19. Bedossa P and Carrat F (2009): Liver biopsy: the best, not the gold standard. J Hepatol; 50: 1-3.

20. EASL-ALEH Clinical Practice Guidelines: (2015): Non-invasive tests for evaluation of liver disease severity and prognosis. Journal of Hepatology; 63: 237-64.

21. Imbert-Bismut $F$, Ratziu $V$, Pieroni $L$, Charlotte F, Benhamou Y, Poynard T (2001): Biochemical markers of liver fibrosis in patients with hepatitis $C$ virus infection: a prospective study. Lancet; 357: 1069- 75 .

22. Wai CT, Greenson JK, Fontana RJ, et al (2003): A simple noninvasive index can predict both significant fibrosis and cirrhosis in patients with chronic hepatitis C. Hepatology; 38: 518-26.

23. Rosenberg $\mathbf{W} M$, Voelker $M$, Thiel $R$, et al (2004): Serum markers detect the presence of liver fibrosis: A cohort study. Gastroenterology; 127: 1704- 13.

24. Lok AS, Ghany MG, Goodman ZD, et al (2005): Predicting cirrhosis in patients with hepatitis $\mathrm{C}$ based on standard laboratory tests: results of the HALT-C cohort. Hepatology; 42: 282- 92.

25. Adams LA, Bulsara $M$, Rossi $E$, et al (2005): Hepascore: an accurate validated predictor of liver fibrosis in chronic hepatitis C infection. Clin Chem; 51: 1867- 73 . 
26. Islam S, Antonsson L, Westin J, Lagging M (2005): Cirrhosis in hepatitis $C$ virusinfected patients can be excluded using an index of standard biochemical serum markers. Scand J Gastroenterol; 40: 86772.

27. Cales P, Oberti F, Michalak S, et al (2005): A novel panel of blood markers to assess the degree of liver fibrosis. Hepatology; 42: $1373-81$

28. Vallet-Pichard A., Mallet V., Nalpas B., Verkarre V., Naplas A., Dhalluin-Venier V., Fontaine H. and Pol S. (2007): FIB-4: an Inexpensive and Accurate Marker of Fibrosis in HCV Infection. Comparison with Liver Biopsy and FibroTest. Hepatology, 46 (1): 32- 6.

29. Angulo $P$, Hui JM, Marchesini $G$, et al (2007): The NAFLD fibrosis score: a noninvasive system that identifies liver fibrosis in patients with NAFLD. Hepatology; 45: 846- 54.

30. Harrison SA, Oliver D, Arnold HL, Gogia S, Neuschwander-Tetri BA (2008): Development and validation of a simple NAFLD clinical scoring system for identifying patients without advanced disease. Gut; 57: 1441-7.

31. Fontana RJ, Goodman ZD, Dienstag JL, et a (2008): Relationship of serum fibrosis markers with liver fibrosis stage and collagen content in patients with advanced chronic hepatitis $C$. Hepatology 2008; 47: 789-98.

32. Parkes J, Guha IN, Roderick $P$, Rosenberg W (2006): Performance of serum marker panels for liver fibrosis in chronic hepatitis C. J Hepatol; 44: 462- 74.

33. Halfon $P$, Bacq $Y$, De Muret A, et al (2007): Comparison of test performance profile for blood tests of liver fibrosis in chronic hepatitis C. J Hepatol; 46: 395-402.

34. Leroy V, Hilleret $M N$, Sturm $N$, et al (2007): Prospective comparison of six non-invasive scores for the diagnosis of liver fibrosis in chronic hepatitis C. J Hepatol; 46: 775-82.
35. Cales $\mathbf{P}$, de Ledinghen $\mathrm{V}$, Halfon $\mathbf{P}$, et al (2008): Evaluating the accuracy and increasing the reliable diagnosis rate of blood tests for liver fibrosis in chronic hepatitis C. Liver Int; 28: 1352-62.

36. Degos F, Perez P, Roche B, et al (2010): Diagnostic accuracy of FibroScan and comparison to liver fibrosis biomarkers in chronic viral hepatitis: a multicenter prospective study (the FIBROSTIC study). J Hepatol; 53: 1013- 21.

37. Guha IN, Parkes J, Roderick P, et al (2008): Noninvasive markers of fibrosis in nonalcoholic fatty liver disease: validating the European Liver Fibrosis Panel and exploring simple markers. Hepatology; 47: $455-60$.

38. Cales P, Laine F, Boursier J, et al (2009): Comparison of blood tests for liver fibrosis specific or not to NAFLD. J Hepatol; 50: 165- 73.

39. Shah AG, Lydecker A, Murray K, Tetri BN, Contos MJ, Sanyal AJ (2009): Comparison of noninvasive markers of fibrosis in patients with non-alcoholic fatty liver disease. Clin Gastroenterol Hepatol; 7: 1104- 12.

40. McPherson S, Stewart SF, Henderson E, Burt AD, Day CP (2010): Simple noninvasive fibrosis scoring systems can reliably exclude advanced fibrosis in patients with non-alcoholic fatty liver disease. Gut; 59: 1265- 9.

41. Poynard $T$, Munteanu M, Imbert-Bismut $F$, et al (2004): Prospective analysis of discordant results between biochemical markers and biopsy in patients with chronic hepatitis C. Clin Chem; 50: 134455.

42. Castera L (2012): Noninvasive methods to assess liver disease in patients with hepatitis B or C. Gastroenterology; 142: 1293-302, e4.

43. Castera L, Foucher J, Bernard PH, et al (2010): Pitfalls of liver stiffness measurement: A 5-year prospective 
study of 13, 369 examinations. Hepatology; 51: 828- 35.

44. Castera L, Le Bail B, Roudot-Thoraval F, et al (2009): Early detection in routine clinical practice of cirrhosis and oesophageal varices in chronic hepatitis C: comparison of transient elastography (FibroScan) with standard laboratory tests and non-invasive scores. J Hepatol; 50: 59-68.

45. Boursier J, de Ledinghen $\mathrm{V}$, Zarski JP, et al (2011): A new combination of blood test and fibroscan for accurate non-invasive diagnosis of liver fibrosis stages in chronic hepatitis C. Am J Gastroenterol; 106: 1255- 63.

46. Zarski JP, Sturm N, Guechot J, et al (2012): Comparison of nine blood tests and transient elastography for liver fibrosis in chronic hepatitis C: the ANRS HCEP-23 study. J Hepatol; 56: 55- 62.

47. Frau M, Feo C, Feo F, Pascale R (2014): New insights on the role of epigenetic alterations in hepatocellular carcinoma. Journal of Hepatocellular Carcinoma; 1 : 65-83.

48. Zhang $Y$, Jia $Y$, Zheng $R$, Guo $Y$, Wang $Y$, Guo H, Fei M, and Sun Sh (2010): Plasma MicroRNA-122 as a Biomarker for Viral-, Alcohol-, and Chemical-Related Hepatic Diseases. Clinical Chemistry 56:12 183038.

49. Lozano R, Naghavi M, Foreman K, Lim S, Shibuya K, Aboyans V, Abraham J, Adair T, Aggarwal $R$, Ahn SY, Alvarado $M$, Anderson HR, Anderson LM, Andrews KG, Atkinson C, Baddour LM, Barker-Collo S, Bartels DH, Bell ML, Benjamin EJ, Bennett D, Bhalla K, Bikbov B, Bin Abdulhak A, Birbeck G, Blyth F, Bolliger I, Boufous $S$, Bucello C, Burch M, et al (2012): Global and regional mortality from 235 causes of death for 20 age groups in 1990 and 2010: a systematic analysis for the Global Burden of Disease Study 2010. Lancet; 380:2095- 128.

50. Abd El-Wahed M M, Badr Mohamad T, Soliman El Sayed A, Abdou Asmaa G, Taie Doha M (2015): Hepatocellular carcinoma in cirrhotic and noncirrhotic liver: Clinicopathological differences. Menoufia Medical Journal; 28 (3): 71217.

51. Collier J, Sherman M (1998): Screening for hepatocellular carcinoma. Hepatology; 27 (1): 273-8.

52. EASL-EORTC clinical practice guidelines: management of hepatocellular carcinoma. J Hepatol. 2012; 56 (4): 90843.

53. Bruix J, Sherman M (2010): Management of hepatocellular carcinoma: an update. Hepatology; 53 (3): 1020- 2.

54. Fornari $F$, Ferracin $M$, Trerè $D$, Milazzo $M$, Marinelli S, Galassi M, Laura Venerandi, Daniela Pollutri1, Clarissa Patrizi, Alberto Borghi1, Francesco G. Foschi, Giuseppe F. Stefanini, Massimo Negrini (2015): Circulating microRNAs, miR-939, miR595, miR-519d and miR-494, Identify Cirrhotic Patients with HCC. PLOS ONE 10(10): e0141448.

55. Petrelli A, Perra A, Cora D et al. (2014): "MicroRNA/gene profiling unveils early molecular changes and nuclear factor erythroid related factor 2 (NRF2) activation in a rat model recapitulating human hepatocellular carcinoma (HCC)," Hepatology; (1):228- 41.

56. Gui J, Tian $Y$, Wen $X$, Zhang $W$, Zhang $P$, Gao J, et al (2011): Serum microRNA characterization identifies miR-885-5p as a potential marker for detecting liver pathologies. Clin Sci; 120 (5): 183- 93.

57. El Tayebi HM, Hosny KA, Esmat G, Breuhahn K, Abdelaziz Al (2012): miR$615-5 p$ is restrictedly expressed in cirrhotic and cancerous liver tissues and its overexpression alleviates the tumorigenic effects in hepatocellular carcinoma. FEBS Lett.; 586 (19): 330916.

58. Hulf $T$, Sibbritt $T$, Wiklund ED, Bert $S$, Strbenac D, Statham AL, et al (2011). Discovery pipeline for epigenetically deregulated miRNAs in cancer: integration of primary miRNA transcription. BMC Genomics; 12: 54. 